\title{
Web-based interventions for ulcerative colitis and Crohn's disease: systematic review and future directions
}

This article was published in the following Dove Press journal:

Clinical and Experimental Gastroenterology

II May 2015

Number of times this article has been viewed

\author{
Colleen Stiles-Shields' \\ Laurie Keefer ${ }^{2,3}$ \\ 'Department of Preventive \\ Medicine and Center for Behavioral \\ Intervention Technologies, \\ Northwestern University Feinberg \\ School of Medicine, Chicago, IL, USA; \\ ${ }^{2}$ Division of Gastroenterology and \\ Hepatology, ${ }^{3}$ Center for Psychosocial \\ Research in GI, Northwestern \\ University Feinberg School of \\ Medicine, Chicago, IL, USA
}

Correspondence: Laurie Keefer

Department of Medicine-

Gastroenterology and Hepatology,

Northwestern University Feinberg School of Medicine, 676 N St Clair, Suite 1400,

Chicago, IL 606II, USA

Email laurie.keefer@northwestern.edu

\begin{abstract}
Behavioral intervention technologies (BITs), the application of psychological and behavioral interventions through the use of technology, provide the opportunity for clinicians to deliver care through a means that overcomes a number of treatment barriers. Web-based interventions are a subset of BITs developing as promising alternatives to face-to-face delivery of treatments and monitoring for patients with ulcerative colitis (UC) and Crohn's disease (CD). A systematic review of literature resulted in five empirical studies of web-based interventions for UC and CD. Additionally, an informal search of a popular search engine yielded limited, currently available, web-based interventions for patients with UC and CD. Despite being an ideal population for the development and dissemination of online interventions, patients with UC and CD have far less treatment options compared to other behavioral health concerns. However, given the growing body of research involving web-based interventions for other conditions, researchers and clinicians targeting $\mathrm{UC}$ and $\mathrm{CD}$ management and treatment have the benefit of being able to utilize the BIT model, an existing conceptual framework for the development of web-based interventions for both conditions. The BIT model is presented and applied to the treatment of UC and CD, as well as a technology development program, Purple, and usability guidelines to guide clinical researchers in the future development, evaluation, and dissemination of BITs for patients with $\mathrm{UC}$ and $\mathrm{CD}$.
\end{abstract}

Keywords: ulcerative colitis, Crohn's disease, internet interventions, behavioral intervention technologies, BIT model, IBD

\section{Introduction}

Ulcerative colitis (UC) and Crohn's disease (CD) are chronic, relapsing and remitting inflammatory conditions of the intestines that result in debilitating symptoms including abdominal pain and diarrhea. Both conditions are categorized as inflammatory bowel disease (IBD), which affects more than 1.4 million Americans and accounts for more than US $\$ 1.7$ billion in health care costs annually. ${ }^{1} \mathrm{UC}$ and $\mathrm{CD}$ are public health concerns given their association with impaired quality of life, psychological distress, high health care utilization, loss of work, and high financial costs..$^{2-5}$

IBD differs from many other chronic conditions in that, even when patients are optimized medically, disease flares will likely still occur. The chronicity of IBD, often diagnosed in early adulthood, requires patients to continuously cycle through periods of acute symptom management, maintenance and prevention, cancer and risk surveillance, and lifestyle modifications for decades. Self-management programs are therefore difficult to standardize; patients with IBD vary by disease type (eg, CD, $\mathrm{UC}$, indeterminate), location (ie, small bowel/colon/upper gastrointestinal/rectum), 
disease behavior (eg, structuring/fistulizing), presence of extra-intestinal manifestations, surgical history, response to medications, family history/genetic contribution of IBD, disease severity, and flare rates. Disease heterogeneity is further complicated by the extent to which a patient falls into ever-changing definitions of "remission" versus (vs) "flare" states. ${ }^{6}$ Additionally, sociodemographic factors (eg, age, sex, rural vs urban, education, income) and heterogeneity imposed by individual psychological characteristics, self-management and treatment needs are similarly diverse. Finally, IBD can affect one's ability to engage in the very behaviors required for optimal outcome in our current health care system - coordinating care across providers, different hospitals and emergency departments, making decisions based on evidence and physician recommendations, deciphering test results, storing and organizing medications over multiple settings and implementing behavior change in multiple contexts. Disease parameters, psychological well-being, and quality of life are directly affected by where a patient fits in terms of flare vs remission, ${ }^{6}$ their current treatment regimen, ${ }^{7}$ and access to quality care. ${ }^{8}$ Of course, self-management demands vary with the disease cycle and behaviors such as lifelong medication adherence are difficult to capture, predict, or influence out of context.

Effective treatments have been identified for the specific needs of patients with $\mathrm{UC}$ and $\mathrm{CD}$, however several barriers to treatment have been found. Non-adherence has been reported to occur in about $40 \%$ of patients; ${ }^{9}$ a critical factor given that non-adherent patients are up to five times more likely to experience a flare up than their adherent counterparts. ${ }^{10}$ Reasons for medication non-adherence range from forgetting $^{11}$ to impact of side effects. ${ }^{12,13}$ Lack of information is another critical barrier, with patients with UC and CD frequently reporting feeling misinformed and/or needing more education about their illness. ${ }^{14-16}$ Additionally, the burden of travelling to face-to-face interventions is often attributed to attrition. ${ }^{17}$ For some, travel to providers is not feasible. While the incidence and prevalence of IBD is similar across rural and urban regions, morbidity and mortality associated with IBD is climbing in regions in which access to IBD specialists and comprehensive care programs are few and far between, ${ }^{18}$ this is further complicated by racial disparities in access and response to medical therapy. ${ }^{19}$ To address and overcome such barriers for patients with $\mathrm{UC}$ and $\mathrm{CD}$, alternative treatment delivery methods are being explored.

Web-based interventions for behavioral health concerns, including $\mathrm{UC}$ and $\mathrm{CD}$, are developing as promising alternatives to face-to-face delivery of treatments and monitoring.
Web-based interventions are part of a larger category of treatment delivery referred to as behavioral intervention technologies (BITs). BITs are the application of psychological and behavioral interventions through the use of technology to address behavioral, cognitive, and emotional targets that support behavioral health. ${ }^{20}$ Common BIT examples include treatment intervention websites, mobile health applications (apps), and sensors used in activity trackers and smartwatches. ${ }^{21}$ BITs have been used to implement behavior change through self-assessment and monitoring, goal setting, skill building, psychoeducation, and feedback. BITs are a subset of the broader field of eHealth $/ \mathrm{mHealth}$, which refers to the use of communication and information technology to broadly support health care. ${ }^{22}$ The broader category of eHealth/mHealth does not necessarily focus on behavior change; therefore, the term BIT will be employed in discussion of resources for patients with UC and CD.

Past reviews of literature include: 1) a review of online information and education resources for patients with IBD; ${ }^{23} 2$ ) a review and evaluation of the quality of such online resources, ${ }^{24} 3$ ) a review of trends of internet use by patients with IBD to gather disease-specific information; ${ }^{25}$ and 4) a review and meta-analysis of distance management methods in the treatment of IBD. ${ }^{26}$ To our knowledge, there is not a complete and current review of web-based interventions for patients with $\mathrm{UC}$ and CD. In this review, current evidence for web-based interventions will be explored, as well as current resources through a popular search engine, followed by a description of a model that may be used to inform future research and development of web-based interventions for $\mathrm{UC}$ and $\mathrm{CD}$.

\section{Systematic review}

A systematic literature search was conducted. The PubMed/ Medline and Embase abstract databases were searched without a date restriction in June 2014. For the database searches, nine main search components (web-based intervention, internet intervention, mobile intervention, online intervention, online, internet, web, Crohn's disease, and ulcerative colitis) were created by combining subject headings with the "AND" or "OR" operators. Relevance was determined by screening titles and abstracts, and reference lists of relevant articles were screened for further potentially relevant studies. Figure 1 displays the Preferred Reporting Items for Systematic Reviews and Meta-Analyses (PRISMA) flow diagram for the literature search. ${ }^{27}$ Additionally, to further understand the current web-based interventions available to patients with UC and CD, two Google searches were conducted in July 2014. 


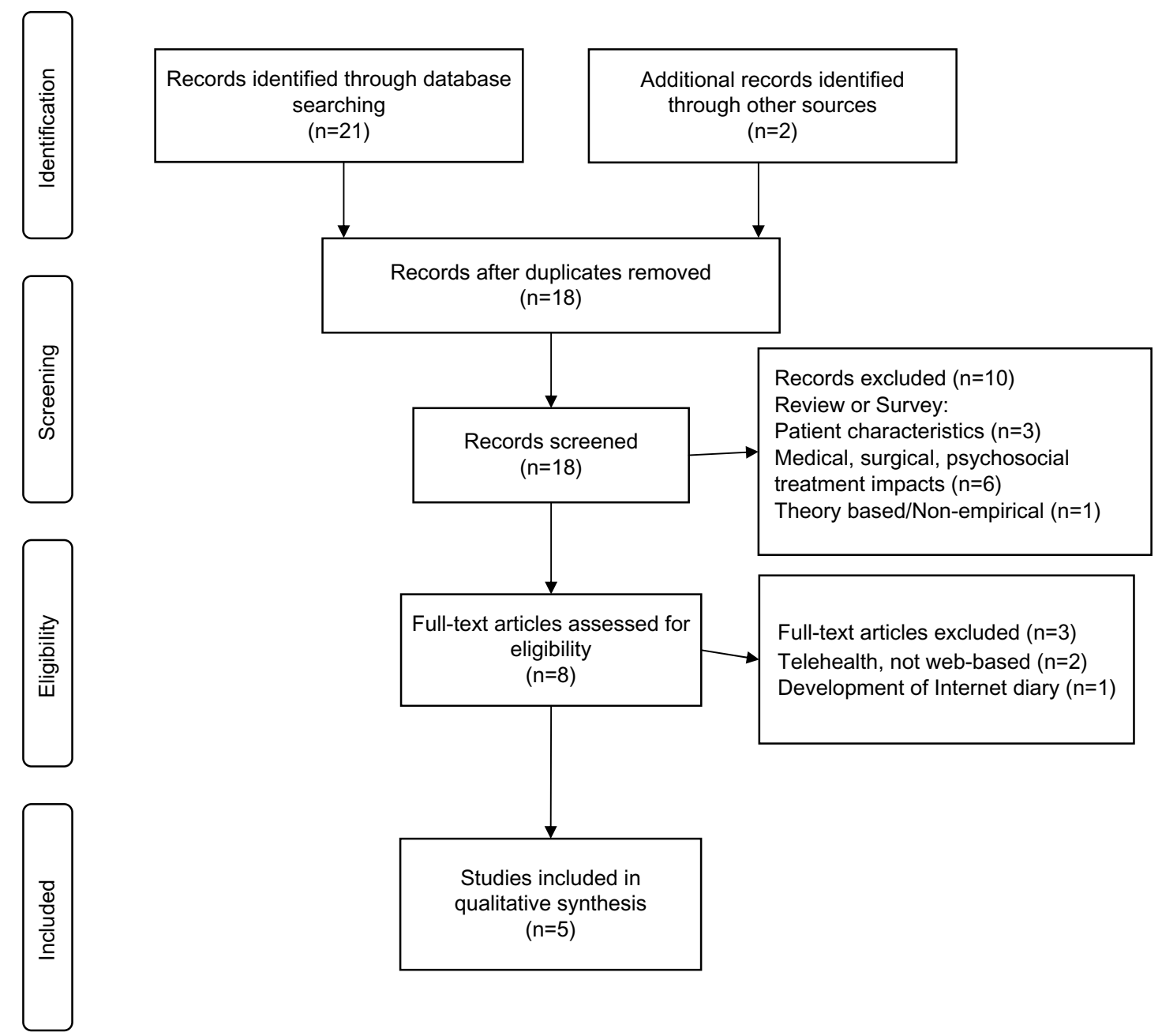

Figure I PRISMA flow diagram for systematic review of web-based interventions for ulcerative colitis and Crohn's disease. Abbreviation: PRISMA, Preferred Reporting Items for Systematic Reviews and Meta-Analyses.

The search components "ulcerative colitis online resources" and "Crohn's disease online resources" were both utilized, yielding eight resources that required full site browsing to determine relevance for web-based interventions. Five studies were included in the qualitative synthesis for meeting the criteria of being empirical evaluations of web-based interventions designed to treat patients with $\mathrm{UC}$ and/or CD.

\section{Literature review}

The first empirical investigation of web-based BITs for UC and CD occurred through web-portals associated with telehealth interventions to increase adherence to treatment. Specifically, through a pilot trial of a home telemanagement system (HAT) for participants diagnosed with IBD. ${ }^{28}$ The HAT system, also known as UC HAT when specific to patients with UC, is comprised of a home unit (ie, laptop and electronic weight scale), a decision support server, and a web-based clinician portal. ${ }^{29}$ Participants were prompted by the home unit to answer questions regarding symptoms, adherence, and side effects, and were also provided diseasespecific psychoeducation. Following each completed interaction, the data were de-identified and encrypted for delivery to the decision support server. The web-based clinician portal provided customized clinical alerts and action plans to providers and email alerts were sent to the nurse coordinator if certain clinical conditions were met based upon the participants' responses. Twenty-five participants enrolled in the 6-month feasibility trial and completed questionnaires related to disease activity, quality of life, and disease-specific knowledge at baseline and end of treatment. Sixty percent of the sample self-reported moderate to severe symptomology 1 month prior to baseline and the majority were on medication throughout the trial. Weekly adherence of self-testing was $91 \%$, with three participants completing less than $80 \%$ of the sessions over 6 months. Twenty-one participants (84\%) reported medication adherence greater than $80 \%$ during 
the course of the trial and significant change in participant disease knowledge, as measured by the Crohn's and Colitis Knowledge Questionnaire (CCKNOW), ${ }^{30}$ occurred over the 6-month intervention. The authors concluded that webbased and telehealth interventions could improve care, adherence, and knowledge for patients with IBD and related disorders. ${ }^{28}$

The same web-based system has been empirically evaluated with a small, randomized trial comparing the UC HAT to the best available care (BAC). ${ }^{29,31}$ BAC was defined as maintaining routine follow-up and receiving written action plans and educational fact sheets. Twenty-five participants and 22 participants were randomized to receive UC HAT or BAC, respectively, for 12 months. Higher rates of attrition occurred for the UC HAT treatment $(44.0 \%)$ than in the BAC treatment (22.7\%). No significant differences between groups were identified in disease activity, quality of life, and adherence at end of treatment. However, after adjusting for baseline disease-specific quality of life and baseline disease knowledge, participants in the UC HAT group had significantly better end of treatment outcomes. The authors concluded that web-supported interventions may improve outcomes for patients with UC; however, web-based interventions that do not require home installation (ie, the home unit used for HAT) should be developed to enhance usability, recruitment, and retention. ${ }^{31}$

Noting the previously described studies and HAT system, Snoei et al designed and evaluated a prototype web-based intervention for patients with UC that employs a paradigm of self-management to enable patients to monitor their own condition. ${ }^{32}$ Fifty-two treatment-seeking adults with UC participated in a 6-month evaluation of a web-based selfmanagement diary for its functionality and usability. The authors identified several functionality and usability features needed for future web-based interventions, including: simple and intuitive login screen, ability of researchers/clinicians to track use beyond tool/survey completion, and incorporating multiple standardized questionnaires to objectively track outcomes. The authors also identified that referring physicians were often biased towards referrals to individuals with higher levels of education and self-reported comfort with using technology. Finally, the authors concluded that their findings will benefit the future design of web-based interventions for UC, particularly if access through mobile phone apps is also developed. ${ }^{32}$

Elkjaer et al have conducted multiple evaluations of a webbased intervention for patients with UC receiving 5-aminosalicyclic acid treatment (5-ASA), "Constant-Care". 33,34
Constant-Care includes an automatic scoring and grouping of patients' responses to the Simple Clinical Colitis Activity Index ${ }^{35}$ and the Short Inflammatory Bowel Disease Questionnaire. ${ }^{36}$ The results of these questionnaires are displayed as a red, yellow, or green light in the form of a traffic light, to help guide the patient to self-initiated treatment with 5-ASA. ${ }^{33}$ Didactic information is also available, including the following topics: intense symptoms, safety, data input, quality of life, recommended treatment, how to contact the doctor, and UC information. Prior to access to the site, participants were provided face-to-face educational training. A feasibility trial was conducted on 21 patients, resulting in patient self-reported belief they could initiate self-treatment following the education training. Additionally, of the eleven patients who used the site for 3 months, all reported increased disease knowledge, six reported increased treatment quality, and three reported increased quality of life. ${ }^{33}$ Constant-Care was next evaluated in a two-site randomized trial in Denmark (using the Dutch language at this site) and Ireland (using the English language at this site), with 117 participants randomized to using the web intervention and 116 randomized to receive standard care. Outcomes were measured at baseline, 6 months, and 12 months. Compared to the control groups, adherence to 4 weeks of acute treatment was 31\% and 44\% higher for Dutch and Irish Constant-Care participants, respectively. The median relapse duration was 77 days for the control groups and 18 days in the Constant-Care participants. However, there were no differences in groups in relapse frequency, surgery, hospitalization, or other adverse events. ${ }^{34}$ These findings highlight the feasibility and possible benefits of ongoing web-based interventions for IBD patients, even across cultures and languages.

\section{Current online resources}

Given the limited data available on web-based interventions for patients with UC and CD, an informal search of currently available online interventions was conducted. The informal Google search of current resources mainly yielded psychoeducation about $\mathrm{UC}$ and $\mathrm{CD}$ and connections to in-person support groups and online discussion groups. Table 1 displays the resources provided by the top hits for the Google searches. One of the top suggestions was a medication-sponsored resource guide with links to other organizations (eg, the Crohn's and Colitis Foundation of America and WebMD) with the instruction to conduct a keyword search for "ulcerative colitis" on each site for disease-specific information and local support groups. ${ }^{37}$ Additionally, non-moderated online discussion groups for individuals with digestive problems (eg, irritable bowel 
Table I Online resources for patients with ulcerative colitis or Crohn's disease

\begin{tabular}{|c|c|c|c|c|c|c|}
\hline Site & $\begin{array}{l}\text { Web-based } \\
\text { intervention }\end{array}$ & $\begin{array}{l}\text { Disease } \\
\text { information }\end{array}$ & $\begin{array}{l}\text { Medication/treatment } \\
\text { information }\end{array}$ & $\begin{array}{l}\text { Support } \\
\text { group }\end{array}$ & $\begin{array}{l}\text { Discussion } \\
\text { group(s) }\end{array}$ & $\begin{array}{l}\text { Links to other } \\
\text { resources }\end{array}$ \\
\hline Lialda: Web Resources & & & $x$ & & & $x$ \\
\hline Everyday Health & & & & & $x$ & $x$ \\
\hline CCFA Online Support Group & & & & $x$ & & \\
\hline CCFA I'IIBDetermined & & $x$ & $\mathrm{x}$ & & $\mathrm{x}$ & $x$ \\
\hline Shire UCentral & & $x$ & $x$ & & & $x$ \\
\hline Crohn's and Colitis Info & & $\mathrm{X}$ & & & $x$ & $x$ \\
\hline Webicina & & & & & $\mathrm{x}$ & $\mathrm{x}$ \\
\hline
\end{tabular}

Abbreviation: CCFA, Crohn's and Colitis Foundation of America.

syndrome, constipation, abdominal distention) were available for membership and participation. ${ }^{38}$ Finally, the Crohn's and Colitis Foundation of America offered an online support group involving 4 weeks of moderated 90 -minute sessions covering specific IBD-related topics and participant discussions. ${ }^{39}$ Additionally, this group also provides additional resources in their "IBDetermined" series, including a social networking component called "The Wall", enabling users to post accomplishments and view others' posts. ${ }^{40}$ The informal search did not yield any web-based interventions for improved adherence, quality of life, or research opportunities for developing webbased interventions.

\section{Future directions for web-based interventions}

Web-based interventions present a unique opportunity for clinicians to provide patients with $\mathrm{UC}$ and $\mathrm{CD}$ treatment and monitoring through a delivery mechanism that overcomes multiple barriers to care. Despite being an ideal population for the development and dissemination of online interventions, patients with UC and CD have far less treatment options compared to other behavioral health concerns. Indeed, a systematic review only yielded five empirical evaluations of web-based interventions for patients with UC and CD. More resources for this population are critically needed. However, given the growing body of research involving web-based interventions for other conditions, researchers and clinicians targeting UC and CD management and treatment have the benefit of being able to utilize existing conceptual frameworks for the development, evaluation, and dissemination of web-based interventions for both conditions.

\section{The BIT model: recommendations for future research in web-based interventions for IBD}

Most BITs have been developed primarily through applying behavioral and psychological theories that have been effective in face-to-face treatments and using developer intuition to instantiate these theories into applications. ${ }^{41}$ Behavioral and psychological theories provide guidance regarding the relationship between patient behaviors and the attainment of ultimate treatment goals, and may be helpful in determining proximal intervention aims, such as increasing positive health maintenance behaviors, but they are less helpful in guiding the design of web-based interventions that can influence cognitions and behavior in behavioral medicine. To meet this need in other chronic conditions, Mohr et al proposed the BIT model. ${ }^{42}$

The BIT model supports the "what", "how", and "when", in translating clinical aims and behavioral strategies into BIT technologies. This model defines the instantiation of behavioral strategies in web-based interventions as including three technological components: 1) elements (the "what"), which are components of a BIT, such as information delivery components, logging tools (ie, to allow the user to input data), reports that typically provide feedback (eg, from logged data); 2) characteristics (the "how") are modifications to elements, such as providing information via text, visualization, or audio aimed at improving the usability of BIT elements; and 3) workflow (the "when") defines how a user progresses through a BIT. ${ }^{42}$ Figure 2 presents an example of how a BIT specific to the treatment of UC and CD may be developed through the use of this framework.

Figure 3 demonstrates a single interaction with a single BIT element to move from a current state to a desired future state and applies this directly to how an individual face-toface interaction between a clinician and a patient with UC or $\mathrm{CD}$ may be conceptualized through a single interaction with a BIT element. Each interaction with the BIT can be thought of as an attempt to move a user's state prior to initiating an interaction with the BIT, the "current state", to a "future state" that reflects an intended consequence of the interaction, such as increased motivation to engage in a positive behavior. Over time, these single interactions are intended 


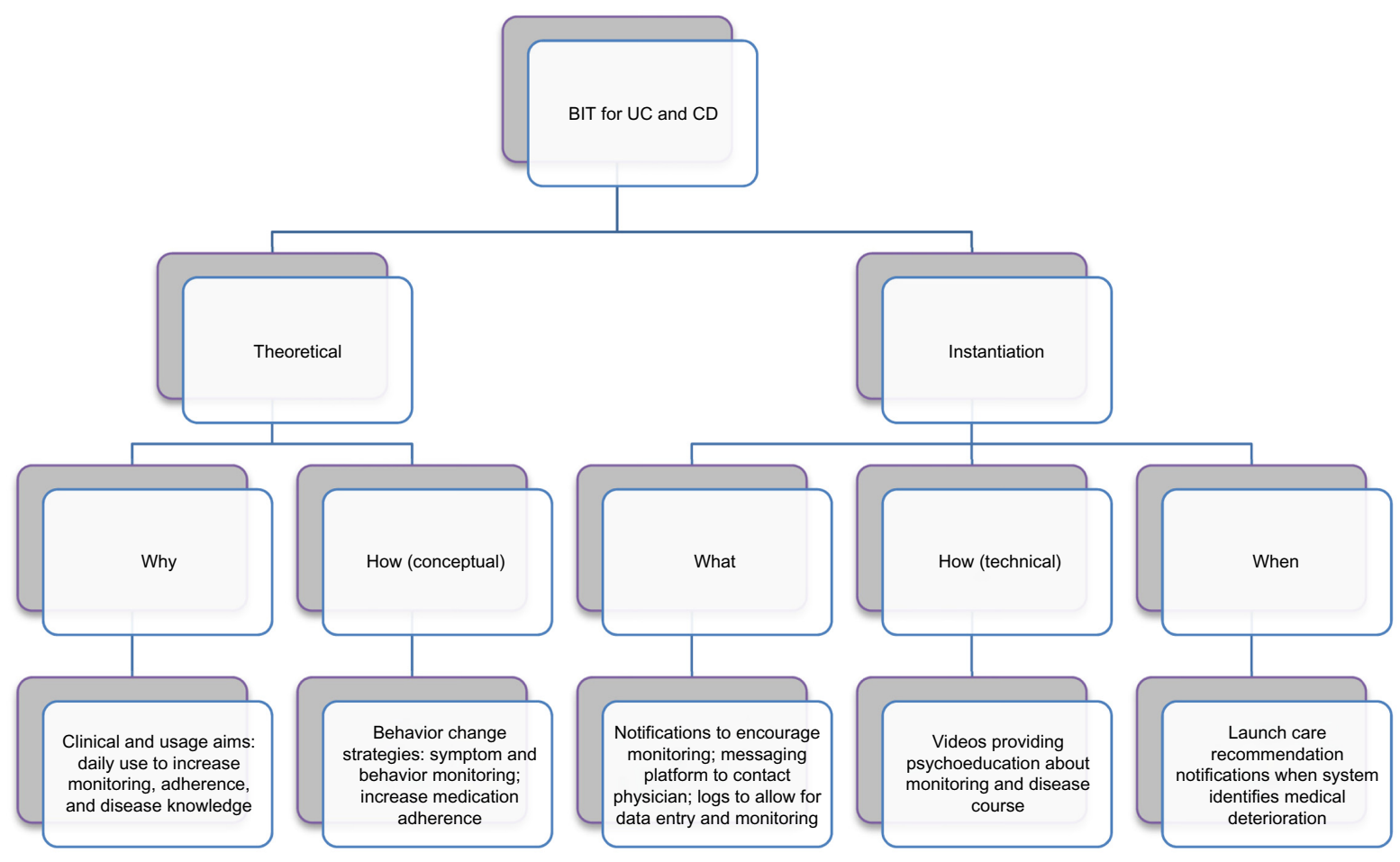

Figure 2 BIT model framework applied to development of a BIT for treatment and monitoring of UC and CD.

Abbreviations: BIT, behavioral intervention technology; UC, ulcerative colitis; $\mathrm{CD}$, Crohn's disease.

to have an additive effect that achieves the broader treatment goals. ${ }^{42}$ This process is similar to face-to-face interactions a physician or clinician has with a patient with UC or CD, working over individual sessions to over time help patients reach remission.

\section{Common concerns in the development of BITs}

While noting the benefit and applicability of BITs for their patients, some clinicians may also be wary of developing and implementing a BIT given the considerable challenges

Interaction with a BIT element to alter a user's state from a current state to a desired future state

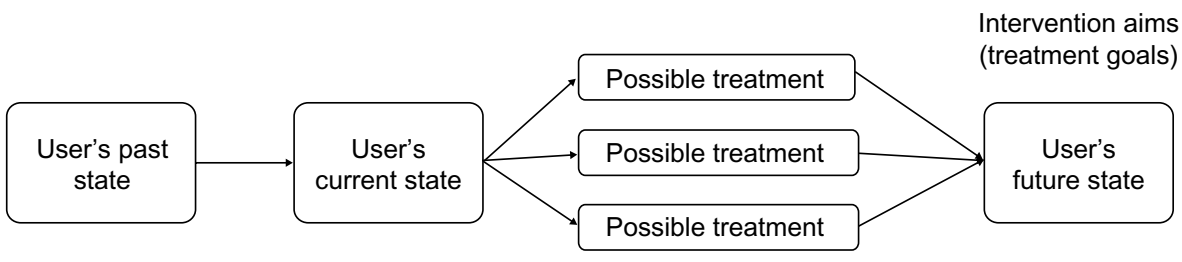

Application of BIT model to how an individual face-to-face interaction between a clinician and a patient with UC or CD may be conceptualized through a single interaction with a BIT element

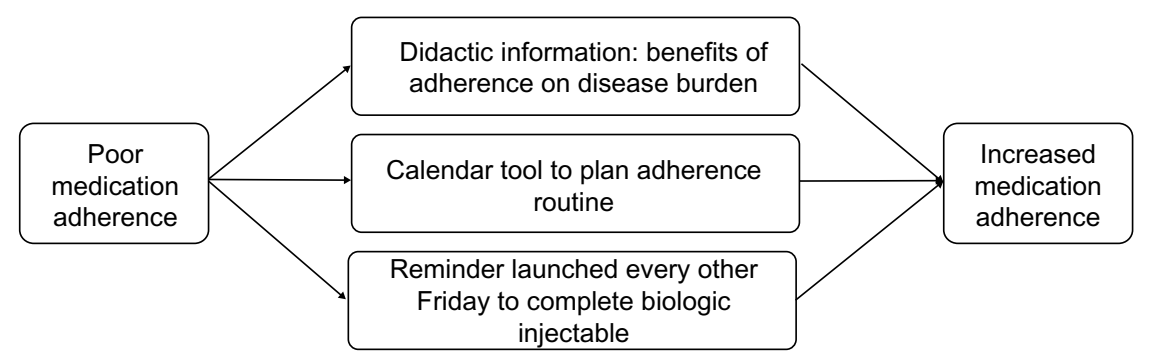

Figure 3 The BIT model and application to interventions for patients with ulcerative colitis (UC) and Crohn's disease (CD). Abbreviation: BIT, behavioral intervention technology. 
associated with this process. ${ }^{43}$ BIT research is typically transdisciplinary, requiring expertise from many fields, such as clinical researchers, who often develop the intervention, and technologists who create the BIT. For example, at our institution, "Purple", an iteratively constructed system, has been designed to address the needs of those interested in creating, deploying, and using BITs. ${ }^{44}$ Purple aims to support the creation of web-based apps aimed at supporting behavior change by providing a framework for the development of BITs that is modular and able to be repurposed for researchers. ${ }^{44}$

Purple has many essential elements and optional elements for researchers to choose for their project. As clinical researchers often do not have programming capabilities, Purple provides content authorship tools, which allow those with limited technological sophistication to directly participate in the development process. Content authorship refers to anything provided to a patient or user (eg, didactic material or assessments in the form of text, video, audio). How (ie, calendars vs graphs for patient feedback) and when (ie, progression rules) content is displayed are also provided as options to clinical researchers, enabling those in this role to make specific decisions about their patients' experience in BIT interactions.

User management is also an essential element for researchers. Purple's user management feature allows the BIT to track data, such as logins and lengths of use, and to provide this information for individual users to the researchers while maintaining privacy and security. Usage and clinical outcome data may be provided to clinical researchers through raw data dumps in a program such as Excel, or through accessed databases that allow for real-time data analysis. More details of options for researchers are available elsewhere, ${ }^{44}$ however these details provide insight into existing platforms for researchers to use to develop, evaluate, and disseminate more BITs for UC and CD.

Another concern clinical researchers may have beyond programming needs is how patients may understand and use BITs. User-centered design and usability testing are methods of evaluation that involve testing users' interactions with a product and system to improve BIT design, ensuring that the intervention is intuitive and easy to use. Usability testing can be designed employing standards based on the International Standards Organization (ISO 9241-11), ${ }^{45}$ which define how to identify the information necessary to take into account when specifying or evaluating usability in terms of measures of user performance and satisfaction. Usability testing is an iterative process in which small groups of participants evaluate the BIT, problems are identified, fixes are made, and a new round of patients are brought in to evaluate the BIT. An example of some features evaluated in usability testing include: learnability (ease with which use is learned, objectively measured by clocktime), effectiveness (successful performance of tasks divided by number of tasks attempted), efficiency (use once task is learned, measured by clocktime), errors (measured by error rates and recovery time from errors), memorability (ease with which user can return to system without relearning, measured by failure rate on second use), and user satisfaction (measured by a questionnaire, such as the After-Scenario Questionnaire). ${ }^{46}$ Through this process, identified usability problems may be addressed to ensure patient usability of BITs for UC and CD.

\section{Extending care to smartphones}

Web-based BITs have demonstrated efficacy across a broad range of mental and behavioral health outcomes. ${ }^{21}$ However, barriers to this delivery method (eg, needing to be in front of a computer) impact uptake and usage. Therefore, a growing body of research is examining the use of mobile and smartphones to deliver interventions, which offer the potential to provide a near continuous connection between a care system and the patient. Smartphones are rapidly increasing in computing capacity and dropping in cost, and forecasters predict that they will become the dominant platform for communications and web access in the coming years. ${ }^{47}$ The use of health apps is growing rapidly. In 2013, over 40,000 health apps had been identified. ${ }^{48}$ An example of an IBD-specific health app is GI Buddy, an app intended to help patients track foods and overall wellness. ${ }^{49}$ The mobile phone is becoming a primary platform for the delivery of BITs, one that has the potential of overcoming multiple barriers to treatment access.

BITs in the form of mobile and web-based apps may provide more opportunities to provide treatment and maintenance to those with patients with UC and CD, whether as separate or combined delivery mechanisms. Indeed, mixing of multiple delivery technologies is being conceptualized by Linn et al, who recently proposed a theoretical and evidencebased multimedia intervention to improve medication adherence involving an online preparatory assessment, tailored interpersonal communication, and tailored text messaging..$^{50}$ More research is required to identify how mixing multiple BIT delivery technologies may impact patient usage and overall clinical outcomes based on individual needs. This future body of research will move the field towards the goal of personalized medicine for patients with IBD, in which a 
patient would be given the treatment option that would offer the greatest likelihood of use and improvement based on their symptoms, comorbid medical and psychological conditions, and lifestyle. ${ }^{51}$

\section{Conclusion}

This review provided a critical overview of the existing empirical evidence for web-based interventions for patients with UC and CD. Only four studies are currently present in the literature investigating the development and evaluation of web-based interventions. Additionally, an informal search of the Google search engine yielded limited options for patients with IBD seeking treatment delivered via the Internet.

The lack of data regarding web-based interventions for patients with UC and CD is problematic, given the impact of non-adherence in this population. Non-adherence is attributed to treatment barriers including travel, misinformation, side effect management, and forgetting. ${ }^{11-14,17}$ BITs provide a unique opportunity to deliver interventions in which clinical researchers have demonstrated efficacy through a means that overcomes several barriers to care. The BIT model is presented as a framework for the development, evaluation, and dissemination of web-based interventions for patients with UC and CD. ${ }^{42}$ Additionally, systems developed by Purple and usability testing standards established by the ISO provide a way for clinical researchers to overcome barriers believed to exist for them to develop BITs for the treatment and maintenance of their patients. ${ }^{44,45}$

Future research is necessary to better understand how BITs can serve the many treatment and maintenance needs of patients with UC and CD. Additionally, it is important to also explore the needs of treating clinicians and clinical researchers in receiving BIT usage and outcome data specific to UC and CD. Finally, future research must also explore the delivery of BITs through multiple technologies, such as smartphones, to continue to bolster treatment reach and effectiveness.

\section{Disclosure}

This research was supported by a grant from the National Institute of Mental Health F31 MH106321 (PI: StilesShields). The authors have no conflict of interest to report.

\section{References}

1. Park KT, Bass D. Inflammatory bowel disease-attributable costs and cost-effective strategies in the United States: a review. Inflamm Bowel Dis. 2011;17(7):1603-1609.
2. Gibson PR, Vaizey C, Black CM, et al. Relationship between disease severity and quality of life and assessment of health care utilization and cost for ulcerative colitis in Australia: A cross-sectional, observational study. J Crohns Colitis. 2014;8(7):598-606.

3. Nurmi E, Haapamaki J, Paavilainen E, Rantanen A, Hillila M, Arkkila P. The burden of inflammatory bowel disease on health care utilization and quality of life. Scand J Gastroenterol. 2013;48(1):51-57.

4. Guthrie E, Jackson J, Shaffer J, Thompson D, Tomenson B, Creed F. Psychological disorder and severity of inflammatory bowel disease predict health-related quality of life in ulcerative colitis and Crohn's disease. Am J Gastroenterol. 2002;97(8):1994-1999.

5. Rubin DT, Mody R, Davis KL, Wang CC. Real-world assessment of therapy changes, suboptimal treatment and associated costs in patients with ulcerative colitis or Crohn's disease. Alimentary Pharmacol Ther. 2014;39(10):1143-1155.

6. Pihl-Lesnovska K, Hjortswang H, Ek AC, Frisman GH. Patients' perspective of factors influencing quality of life while living with Crohn disease. Gastroenterol Nurs. 2010;33(1):37-44.

7. Malik BA, Gibbons K, Spady D, Lees G, Otley A, Huynh HQ. Health-related quality of life in pediatric ulcerative colitis patients on conventional medical treatment compared to those after restorative proctocolectomy. Int J Colorectal Dis. 2013;28(3):325-333.

8. van der Eijk I, Vlachonikolis IG, Munkholm P, et al. The role of quality of care in health-related quality of life in patients with IBD. Inflamm Bowel Dis. 2004;10(4):392-398.

9. Kane SV, Cohen RD, Aikens JE, Hanauer SB. Prevalence of nonadherence with maintenance mesalamine in quiescent ulcerative colitis. $\mathrm{Am}$ J Gastroenterol. 2001;96(10):2929-2933.

10. Kane S, Huo D, Aikens J, Hanauer S. Medication nonadherence and the outcomes of patients with quiescent ulcerative colitis. Am J Med. 2003;114(1):39-43.

11. Sewitch MJ, Abrahamowicz M, Barkun A, et al. Patient nonadherence to medication in inflammatory bowel disease. Am J Gastroenterol. 2003;98(7):1535-1544.

12. Cross RK, Lapshin O, Finkelstein J. Patient subjective assessment of drug side effects in inflammatory bowel disease. J Clin Gastroenterol. 2008;42(3):244-251.

13. Cross RK, Wilson KT, Binion DG. Polypharmacy and Crohn's disease. Aliment Pharmacol Ther. 2005;21(10):1211-1216.

14. Martin A, Leone L, Castagliuolo I, Di Mario F, Naccarato R. What do patients want to know about their inflammatory bowel disease? Ital $J$ Gastroenterol. 1991;24(9):477-480.

15. Friedman S, Cheifetz AS, Farraye FA, et al. Factors that affect adherence to surveillance colonoscopy in patients with inflammatory bowel disease. Inflamm Bowel Dis. 2013;19(3):534-539.

16. García-Sanjuán S, Lillo-Crespo M, Sanjuán-Quiles Á, Gil-González D, Richart-Martínez M. Life Experiences of People Affected by Crohn's Disease and Their Support Networks Scoping Review. Clin Nurs Res. Epub Jul 23, 2014.

17. Hommel KA, Herzer M, Ingerski LM, Hente E, Denson LA. Individually tailored treatment of medication nonadherence. J Pediatr Gastroenterol Nutr. 2011;53(4):435-439.

18. Mawdsley JE, Irving PM, Makins RJ, Rampton DS. Optimizing quality of outpatient care for patients with inflammatory bowel disease: the importance of specialist clinics. Eur J Gastroenterol Hepatol. 2006; 18(3):249-253.

19. Nguyen GC, LaVeist TA, Harris ML, Wang MH, Datta LW, Brant SR. Racial disparities in utilization of specialist care and medications in inflammatory bowel disease. Am J Gastroenterol. 2010; 105(10):2202-2208.

20. Burns MN, Mohr DC. eHealth and Behavioral Intervention Technologies. In: Gellman MD, Turner JR, editors. Encyclopedia of Behavioral Medicine. New York: Springer; 2013:659-664.

21. Mohr DC, Burns MN, Schueller SM, Clarke G, Klinkman M. Behavioral Intervention Technologies: Evidence review and recommendations for future research in mental health. Gen Hosp Psychiatry. 2013;35(4): 332-338. 
22. Oh H, Rizo C, Enkin M, Jadad A. What is eHealth (3): a systematic review of published definitions. J Med Internet Res. 2005;7(1):e1.

23. Bernard A, Langille M, Hughes S, Rose C, Leddin D, Veldhuyzen van Zanten S. A systematic review of patient inflammatory bowel disease information resources on the World Wide Web. Am J Gastroenterol. 2007;102(9):2070-2077.

24. Langille M, Bernard A, Rodgers C, Hughes S, Leddin D, van Zanten SV. Systematic review of the quality of patient information on the internet regarding inflammatory bowel disease treatments. Clin Gastroenterol Hepatol. 2010;8(4):322-328.

25. Fortinsky KJ, Fournier MR, Benchimol EI. Internet and electronic resources for inflammatory bowel disease: a primer for providers and patients. Inflamm Bowel Dis. 2012;18(6):1156-1163.

26. Huang VW, Reich KM, Fedorak RN. Distance management of inflammatory bowel disease: systematic review and meta-analysis. World $J$ Gastroenterol. 2014;20(3):829-842.

27. Moher D, Liberati A, Tetzlaff J, Altman DG, Prisma Group. Preferred reporting items for systematic reviews and meta-analyses: the PRISMA statement. PLoS Med. 2009;6(7):e1000097.

28. Cross RK, Finkelstein J. Feasibility and acceptance of a home telemanagement system in patients with inflammatory bowel disease: a 6-month pilot study. Dig Dis Sci. 2007;52(2):357-364.

29. Cross RK, Finkelstein J. Challenges in the design of a Home Telemanagement trial for patients with ulcerative colitis. Clin Trials. 2009;6(6): 649-657.

30. Eaden JA, Abrams K, Mayberry JF. The Crohn's and Colitis Knowledge Score: A test for measuring patient knowledge in inflammatory bowel disease. Am J Gastroenterol. 1999;94(12):3560-3566.

31. Cross RK, Cheevers N, Rustgi A, Langenberg P, Finkelstein J. Randomized, controlled trial of home telemanagement in patients with ulcerative colitis (UC HAT). Inflamm Bowel Dis. 2012;18(6): 1018-1025.

32. Snoei L, van Bodegraven A, Oldenburg B, Stijnen T, Kaptein AA. Prototype evaluation of a self-management Internet diary for patients with ulcerative colitis. Patient Prefer Adherence. 2009;3:179-187.

33. Elkjaer M, Burisch J, Avnstrom S, Lynge E, Munkholm P. Development of a Web-based concept for patients with ulcerative colitis and 5-aminosalicylic acid treatment. Eur J Gastroenterol Hepatol. 2010; 22(6):695-704.

34. Elkjaer M, Shuhaibar M, Burisch J, Bailey Y, Scherfig H, Laugesen B, et al. E-health empowers patients with ulcerative colitis: a randomised controlled trial of the web-guided 'Constant-care' approach. Gut. 2010; 59(12):1652-1661.

35. Walmsley RS, Ayres RC, Pounder RE, Allan RN. A simple clinical colitis activity index. Gut. 1998;43(1):29-32.

36. Irvine EJ, Zhou Q, Thompson AK. The Short Inflammatory Bowel Disease Questionnaire: a quality of life instrument for community physicians managing inflammatory bowel disease. CCRPT Investigators. Canadian Crohn's Relapse Prevention Trial. Am J Gastroenterol. 1996;91(8):1571-1578.
37. Shire US Inc [homepage on the Internet]. Lialda (mesalamine) $1.2 \mathrm{~g}$ delayed release tablets. Web Resources Wayne, PA: Shire US Inc.; 2014. Available from: http://www.lialda.com/ulcerative-colitiswebsites.aspx. Accessed February 10, 2015.

38. Everyday Health Media LLC [homepage on the Internet]. Digestive Health; 2014. Available from: http://www.everydayhealth.com/forums/ digestive-health.html. Accessed February 10, 2015.

39. Crohn's and Colitis Foundation of America [homepage on the Internet]. CCFA Online Support Group. Available from: http://www.ccfacommunity.org/chatseries.aspx. Accessed February 10, 2015.

40. Crohn's and Colitis Foundation of America [homepage on the Internet]. I'll Be Determined. Available from: http://www.ibdetermined.org/. Accessed February 10, 2015.

41. Riley WT, Rivera DE, Atienza AA, Nilsen W, Allison SM, Mermelstein R. Health behavior models in the age of mobile interventions: are our theories up to the task? Transl Behav Med. 2011;1(1):53-71.

42. Mohr DC, Schueller SM, Montague E, Burns MN, Rashidi P. The Behavioral Intervention Technology Model: An integrated conteptual and technological framework for eHealth and mHealth interventions. J Med Internet Res. 2014;16(6):e146.

43. Schueller SM, Munoz RF, Mohr DC. Realizing the potential of Behavioral Intervention Technologies. Current directions in Psychological Science. 2013;22:478-483.

44. Schueller SM, Begale M, Penedo FJ, Mohr DC. Purple: a modular system for developing and deploying behavioral intervention technologies. J Med Internet Res. 2014;16(7):e181.

45. Tullis T, Albert B. Measuring the User Experience: Collecting, Analyzing, and Presenting Usability Metrics. Burlington, MA: Morgan Kaufmann Publishers; 2008.

46. Lewis JR. An After-Scenario Questionnaire for usability studies: Psychometric evaluation over three trials. ACM SIGCHI Bulletin. 1991;23(1):79-81.

47. National Research Group. State of the Media: US Digital Consumer Report Q3-Q4 Nielsen Company; 2011. Available from: http://www. nielsen.com/us/en/insights/reports/2012/us-digital-consumer-report. html. Accessed December 15, 2014.

48. IMS Institute for Healthcare Informatics [homepage on the Internet]. Aitken M. Patient Apps for Improved Healthcare: From Novelty to Mainstream. IMS Institute for Healthcare Informatics; 2013. Available from: https://developer.imshealth.com/Content/pdf/IIHI_Patient_Apps_ Report.pdf. Accessed February 10, 2015.

49. Crohn's and Colitis Foundation of America [homepage on the Internet]. GI Buddy; 2012. Available from: https://gibuddy.ibdetermined.org/. Accessed February 10, 2015.

50. Linn AJ, van Weert JC, Smit EG, Perry K, van Dijk L. 1+1=3? The systematic development of a theoretical and evidence-based tailored multimedia intervention to improve medication adherence. Patient Educ Couns. 2013;93(3):381-388.

51. Paul GL. Strategy of outcome research in psychotherapy. $J$ Consult Psychol. 1967;31(2):109-118.

Clinical and Experimental Gastroenterology

\section{Publish your work in this journal}

Clinical and Experimental Gastroenterology is an international, peerreviewed, open access journal, publishing all aspects of gastroenterology in the clinic and laboratory, including: Pathology, pathophysiology of gastrointestinal disease; Investigation and treatment of gastointestinal disease; Pharmacology of drugs used in the alimentary tract;

Immunology/genetics/genomics related to gastrointestinal disease. This journal is indexed on CAS. The manuscript management system is completely online and includes a very quick and fair peer-review system. Visit http://www.dovepress.com/testimonials.php to read real quotes from published authors. 